\title{
Numerical investigation of thermal anti-icing system of aircraft wing
}

\begin{abstract}
There has always been an ongoing effort to improve aircraft anti-icing systems. Aircraft Icing poses a dangerous to the performance and safety, so it has a great concern for the airplane manufacturing and Airliners. The geometry of anti-icing system consists of a piccolo tube inside a swept wing with three rows of round jets based on NACA 23012 air foil. Commercial ANSYS CFD software is used to solve a compressible internal airflow, an external cold airflow and the thermal conduction in the solid skin. By modelling only the effects of conductive, viscous and convective heat transfer in a dry atmosphere the complexity of this procedure conjugate heat transfer is reduced. Used three dimensional Navier-Stokes computer code to simulate the jet flow impinging with circular configuration and heat transfer. The flow field of all turbulent regions was modelled by using the twoequation $\mathrm{k} \omega$ Shear Stress Transport (SST) turbulence model. This research work indicates a strong potential of using CFD in dynamic of partial wing segment including thermal anti-icing system model at different external flow parameters development and validation.
\end{abstract}

Volume 6 Issue 2 - 2020

\author{
Ahmed Hassaani, ' Ahmed F. Elsayed, ${ }^{2}$ Essam \\ E. Khalil ${ }^{3}$ \\ 'PhD student, Department of Aeronautical Engineering, Institute \\ of Aviation and Technology, Egypt \\ ${ }^{2}$ Professor of Mechanical Engineering, Zagazig University, Egypt \\ ${ }^{3}$ Professor of Mechanical Engineering, Cairo University, Egypt
}

Correspondence: Ahmed Hassaani, PhD student, Department of Aeronautical Engineering, Institute of Aviation and Technology, Cairo, Egypt, Tel +201003707525,

Email ahmed.hassaany84@yahoo.com

Received: January 08, 2020 | Published: May 05, 2020

Keywords: computational fluid dynamics, wing anti-icing, conjugate heat transfer, thermal anti-icing, bleed air

Abbreviations: RANS, reynolds average navier-stokes; TE, trailing edge; CFD, computational fluid dynamics; LE, leading edge; AIS, anti-icing system; WLE, wing leading edge; IRT, icing research tunnel

\section{Introduction}

When an aircraft flies through clouds under icy environments, supercooled droplets of water at temperatures below the freezing point can affect its surfaces and cause ice accretion. A mixture of freezing circumstances and moisture content in the atmosphere causes icing on aircraft. Protection of an aircraft from the adverse effect of ice accretion on wing surface is a significant design problem for flight. Ice formation is a very dangerous condition, as it affects the aerodynamic wing design and this state is important to prevent. ${ }^{1}$ In recent years, the practical concept of icing and anti-icing, such as the impingement of supercooled large droplets (SLD), the flow and heat transfer of runback water in glazing or mixing icing, and the effect of roughness on ice accretion have all been gradually developed to enhance icing detection or anti-icing system design. ${ }^{2}$ If moisture affects an aircraft's forward facing surfaces and these surfaces are at or below $0^{\circ} \mathrm{C}$, an ice build-up may seriously change the aerodynamic characteristics. This refers in particular to tiny objects with greater catch rate effectiveness than large ones, since tiny quantities of ice will generate relatively larger shape changes, posing a significant performance and safety risk.

The geometry of anti-icing system Figure 1 consists of a piccolo tube with three rows of round jets inside the wing based on airfoil NACA23012 Figure 2 According to Illinois University database at Urbana-Champaign. ${ }^{3}$ The aircraft propulsion system is penalized by the anti-icing scheme because it uses hot bleed air to prevent the ice formation on the wing. ${ }^{4,5}$ Therefore, it is very essential to understand the demands for hot airflow by defining the processes of the heat transfer of impingement jet.

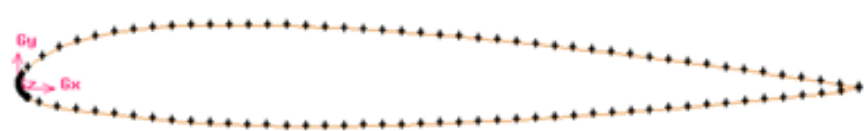

Figure I NACA 23012 airfoil wing section. ${ }^{3}$

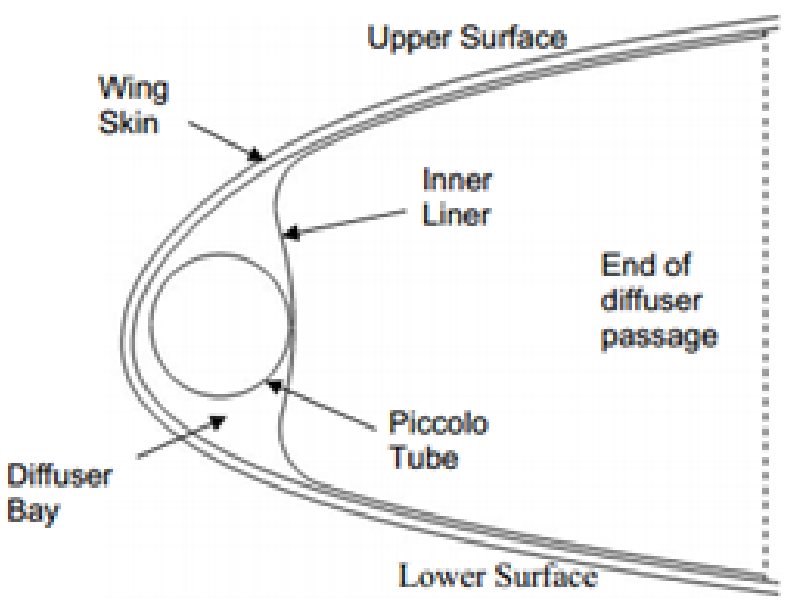

Figure 2 anti-icing system. ${ }^{5}$

The real quantity and shape of the ice build-up depend on surface temperature resulting from an energy equilibrium resulting from heat input from viscous or kinetic air heating, water droplet kinetic heating and latent fusion heat, and losses from evaporation or sublimation, convection and heating of the impinging particles. The CFD studies described here have been conducted for dry external flow conditions. In the calculations carried out using the commercial Navier-Stokes code ANSYS, a 124-mm Partial Span Model was used. Figure 3,4,5 shows the geometric specifications for the designs. 

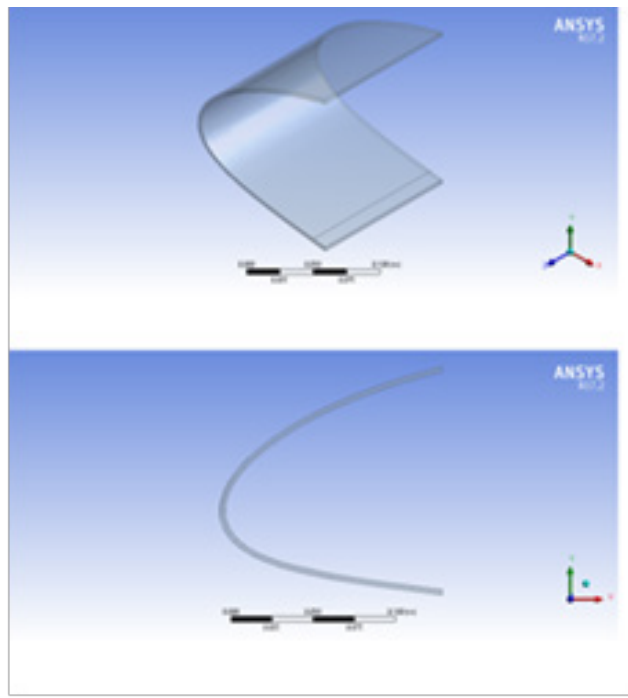

Figure 3 Wing Leading edge.
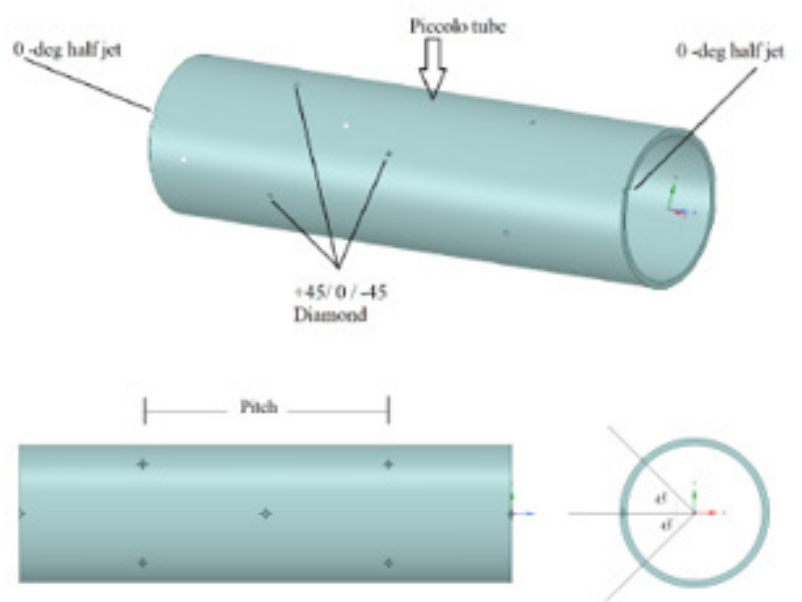

Figure 4 Piccolo tube.
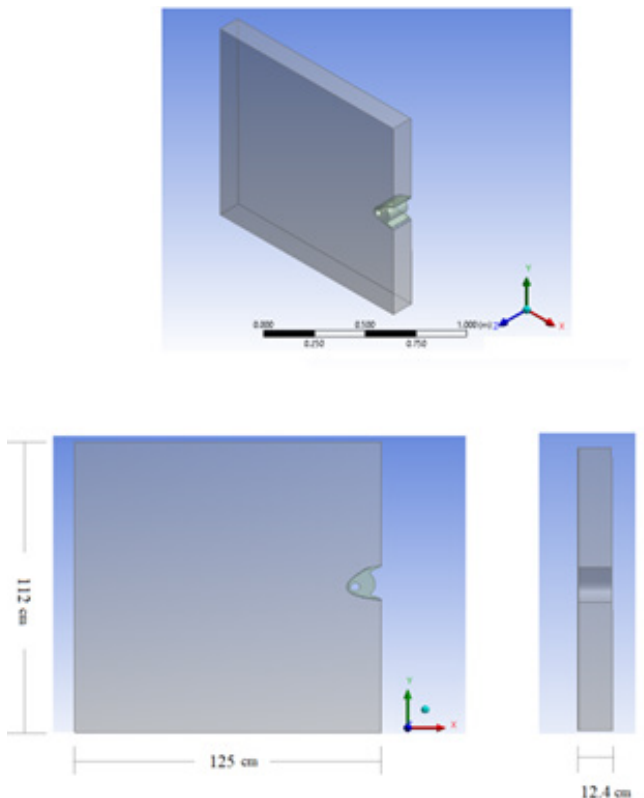

Figure 5 Computational domain geometry's planes $x-y$ and $y-z$.

\section{Numerical method and mathematical model}

The computational fluid dynamics is based on a model includes partial section of the wing LE including inside thermal anti-icing bay. ANSYS CFX 17.2 commercial flow solver has been used for CFD computing. A short presentation is presented below for numerical method and the mathematical model used for calculation.

For CFD commercial ANSYS software was used to perform simulations of heat transfer by bleed air scheme being tested. Finite volume method is used by ANSYS to solve the RANS equations. The governing fluid flow equations include mass, momentum and power conservation. When the flow is turbulent, additional transport equations are used. For computational that represent solid wall region, such as the wing LE skin, heat conduction is calculated only through the wall.

\section{Mathematical model}

Airflow was considered to be compressible and turbulent. It was assumed that air characteristics followed the law of ideal gas:

$$
P=\rho R T
$$

The RANS compressible equations are expressed as follows for eddy-viscosity-based turbulence models:

$$
\begin{gathered}
\frac{\partial \rho}{\partial t}+\nabla \cdot(\rho \vec{V})=0 \\
\nabla \cdot(\rho \cdot \vec{v} \vec{v})=-\nabla p+\nabla \cdot(\bar{\tau})+\vec{F} \\
\frac{\partial(\rho E)}{\partial t}+\nabla \cdot(\vec{v}(\rho E+p))=\nabla \cdot\left[k_{e f f} \nabla T-\sum_{j} h_{j} \vec{J}_{j}+\left(\bar{\tau}_{e f f} \cdot \vec{v}\right)\right]+S_{h} \\
\frac{\partial\left(\rho_{s} h_{s}\right)}{\partial t}=\nabla \cdot(\nabla T)+S_{E}
\end{gathered}
$$

Using the ANSYS CFX 17.2 procedure, the CFD solutions for solid conduction, internal and flow external flow were combined. At air solid interfaces, air temperature was assumed to be equivalent to solid temperature and thermal fluxes were assumed to be preserved. The details equations of $\mathrm{k}-\omega \mathrm{SST}$ turbulence model used to calculate turbulent viscosity. ${ }^{6}$ In using a collocated finite volume technique, turbulence model equations and $(2,4)$ equations were solved. ${ }^{7}$ The law of ideal gas Eq (1) relates density to temperature and pressure. A linearized equations system was constructed and solved from Eq (2) and (3).

\section{Computational methodology}

Simulating AIS generally requires modelling inner region of hot air, the outer (wet or dry) flow region, solid (skin) region and the region of runback water (for wet outer flow). ${ }^{8}$ To determine flow properties, which would satisfy the required equations used to CFD, model this physical phenomenon in the four regions, an iterative method is required.

Dry of cold air was used for outer cooling in the tests conducted with the NACA 23012 airfoil. Therefore, in the thermal analysis conducted with $\mathrm{CFD}$, simulation of the water runback and water impingement impacts was not needed. ${ }^{4}$ Only outer air flow dry region, the internal hot air region, the solid wall area and the combined heat transfer between external flow and internal flow areas were modelled. But the impacts of radiation heat were not included in calculations 
conducted since conduction and convection dominate heat transfer as typical hot air system. ${ }^{4}$

\section{Anti-icing system (AIS)}

The wing Anti-Icing System (AIS) Geometry was based on NACA23012 airfoil with chord length (C) $1.520 \mathrm{~m}$. Figure 5 shows tow dimension cuts in the selected geometry's $y-x$ and $y-z$ planes. The model had a full-length (125-cm high x $12.4-\mathrm{cm}$ wide x 112$\mathrm{cm}$ long). Figure $1 \& 3$ demonstrates the anti-icing system and piccolo tube respectively. The model wing span length was 12.4-cm (double of the piccolo jet holes pitch). Six circular jet holes were modeled of 1.32-mm diameter on the piccolo tube surface and pattern arranged is diamond. Only half a hole at each spanwise end was modeled as necessary for symmetry in the boundary conditions Figure 6.The diameter of piccolo tube was $0.038 \mathrm{~m}$, and it excluded in the domain of internal flow computation.
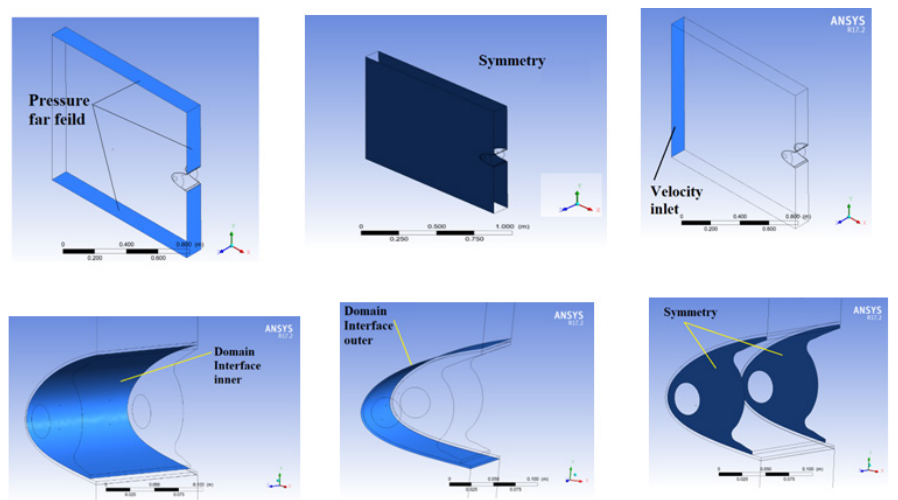

Figure 6 Numerical model boundary condition.

At the later part of the diffuser passage founded between the wing and the inner-liner skins, the hot air domain of the model was terminated, while the 3-mm thick wing LE skin was extended to wing's TE. Note that Teflon ${ }^{\circledR}$ inserts have been used to decrease heat transfer between all wing body skin and LE skin area. These areas were placed on the upper and lower surfaces between 13.5 and 14.5 percent of the wing chord. ${ }^{5}$

The external cooling airflow was represented a dry for calculations. The computing domain is shown in Figure 5. The far field a uniform air temperature and velocity of $268 \mathrm{~K}, 59.2 \mathrm{~ms}^{-1}$ respectively at an attack angle of $0^{\circ}$ was determined uniformly. The external domain on both sides, periodic boundary conditions were created, spaced 0.124 m apart.

\section{Grid generation}

Computational grids described in this document were created using the ANSYS grid generation package. In a graphical interface, ANSYS offers geometry and meshing tools and is able to creating mesh as structured, unstructured and hybrid meshes in 2D- and 3D models. ${ }^{4}$ Thefirst stage in the simulation of CFD must be to examine the impact of mesh size study on the outcomes of the results.

Generally speaking, as more cells are used, the numerical solution will become more accurate, but the use of extra cells also increases the computer memory and the time needed for computing. To guarantee adequate resolution of air flow and the heat transfer characteristics, grid density close walls and areas comprising the jets of hot air was high.
Two pitches of piccolo tube jet holes were used in order to place a big amount of grid points in the hot air jets region to determine the impacts of grid density on numerical results. The grid of model was meshed with airfoil on $x-y$ plane and wingspan along the z-axis. Studies of grid were conducted before starting runs to choice the grid density that was good enough to fix the flow's primary physical characteristics. Table 1 give the grids information used in this simulation research.

Table I Grid size data for resolution study

\begin{tabular}{lcccccc}
\hline \multicolumn{1}{c}{ Case } & I & $\mathbf{2}$ & $\mathbf{3}$ & $\mathbf{4}$ & $\mathbf{5}$ & $\mathbf{6}$ \\
\hline $\begin{array}{l}\text { No of element } \\
\text { in cold domain } \\
\text { (M) }\end{array}$ & 1.11 & 1.34 & 1.34 & 1.34 & 2.2 & 5 \\
$\begin{array}{l}\text { No of element } \\
\text { in wing LE (K) }\end{array}$ & 236.7 & 416.7 & 456.6 & 557.8 & 676.4 & 377 \\
$\begin{array}{l}\text { No of element } \\
\text { in hot domain } \\
\text { (M) }\end{array}$ & 1.55 & 2.55 & 2.84 & 3.59 & 3.35 & 2.3 \\
$\begin{array}{l}\text { Total Number } \\
\text { of Element (M) }\end{array}$ & 2.89 & 4.31 & 4.65 & 5.5 & 6.23 & 7.67 \\
$\begin{array}{l}\text { LE Average } \\
\begin{array}{l}\text { Temperature } \\
\text { (Ok) }\end{array}\end{array}$ & 278.6 & 279.11 & 282 & 319.18 & 321.4 & $\begin{array}{l}\text { Out of } \\
\text { mem } \\
\text { limit }\end{array}$ \\
\hline
\end{tabular}

Six types of mesh are produced to examine the independence of the outcomes from cell number. Table 1 shows the six meshes results of External cold air flow domain, Wing L.E Solid domain and internal hot air flow domain Figures 7, 8 \& 9 respectivelyshows cross-sectional opinions of the grid. The total grid number used in the resolution study of grid was limited by the size of computer ram memory available used for computing. In order to have good agreement computations, the grid with the $5.5 \mathrm{M}$ cells number Figures 7, $8 \& 9$ should be used for the calculations.

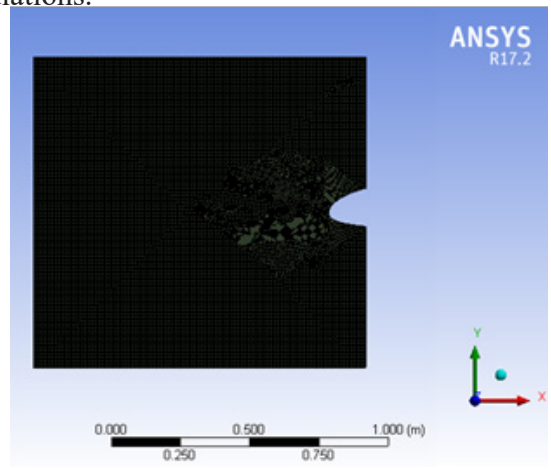

Figure 7 External cold air flow domain.

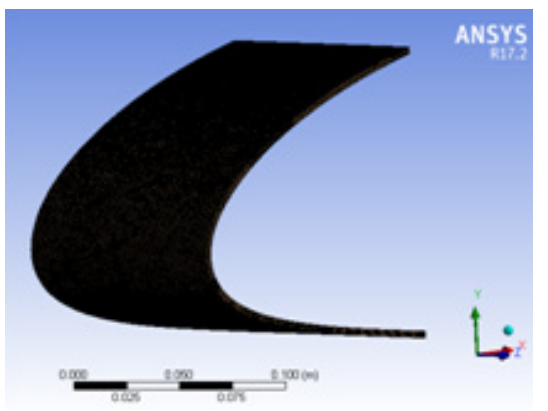




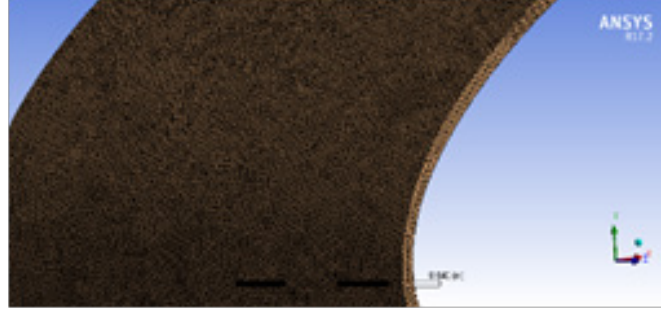

Figure 8 Wing L.E Solid domain.

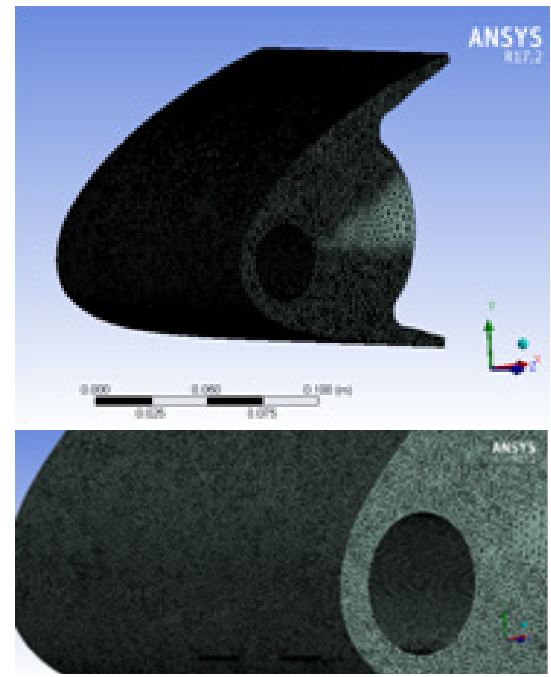

Figure 9 Internal hot air flow domain.

\section{Boundary conditions}

The boundary conditions for calculating inner and external viscous flow included at wall boundaries no-slip condition and fluid boundary inner flow or outer flow condition. On the piccolo tube surface isothermal (steady temperature) boundary condition of the wall was used. Magnitude of velocity and static temperature (velocity-inlet condition B.C) Finally, periodic and symmetry boundary conditions in the span wise direction were used to decrease the domain in order to model only a short segment of real test article.

Because of interaction of piccolo jets, length of the model segment was carefully chosen to be sufficiently long to pick up span flow but also short enough for keeping proper solution with a practicable grid point's number. At top and bottom diffusers of hot region was applied opening boundary condition. Figure 8 illustrates the numerical model boundary condition of a rectangular wing section NACA23012 airfoil

\section{Validation}

This part is dedicated to validating the results of the CFD obtained using ANSYS CFX 17.2 code. Based on earlier experimental results tested at the NASA IRT published by Papadakis,, 95 the impinging jet findings were validated. By comparison the findings of the anti-icing scheme were validated with the present numerical results obtained.

\section{Results and discussion}

The same geometry and dimension of the wing model has been used in all cases. Figure 10 shows the impacts on temperature of LE inner skin. The information from the experiment in Figure 10 corresponds to temperatures reads at LE inner skin Station B Figure 11.
Calculated temperatures have been taken from model at $\mathrm{z}=46.5-\mathrm{mm}$ span distance which half between single and the double jet position. ${ }^{5}$ Note that temperatures calculated at LE skin were extracted from the integrated thermocouples halfway through the thickness of the LE skin emulating the measurements in the experimental configuration. ${ }^{9}$

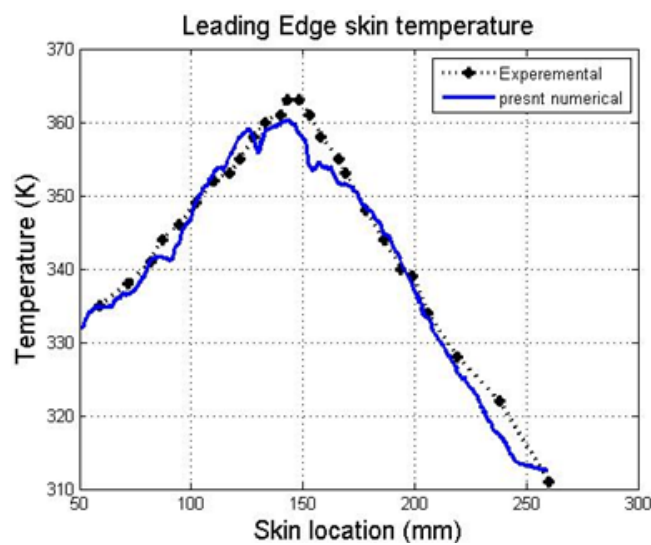

Figure 10 LE skin temperature, Station B.

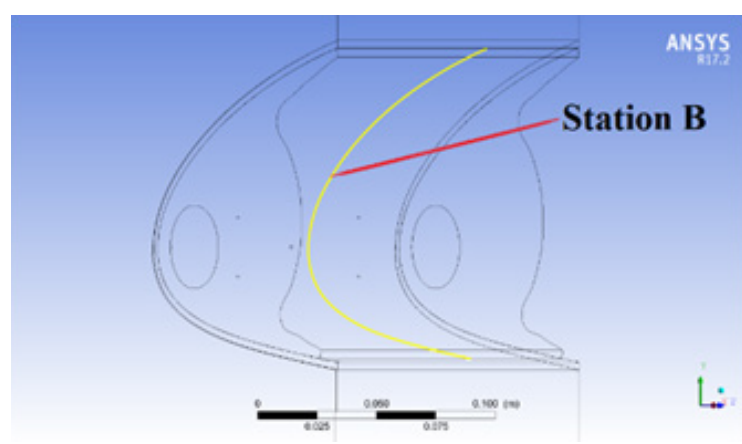

Figure II Station B.

Figure 10 demonstrates that the proper experimental trend was predicted by Papadakis. ${ }^{9}$ In the two cases, surface temperatures were highest near the top edge and slowly decreased from it. At upper surface of the wing was observed that Lower temperatures compared to temperatures recorded along lower surface of the wing. The present CFD results have a better agreement with experimental information when using the CFD. The wing LE temperatures along the bottom surface were correctly calculated with little difference between the experimental and computational data because the external flow over LE airfoil surface is completely turbulent resulted in reduced temperatures of the skin near the LE region compared to experimental information.But the temperature of LE was over-predicted by as much as $5^{\circ} \mathrm{k}$. Also Figure10 shows that at downstream end of top and bottom surfaces, the wing skin temperatures were practically the same. This resulted from the imposition of the same temperature boundary conditions of the experimental.

Other chosen simulation results are displayed in Figures 12, 13. In Figure 12 the streamlines displayed Indicate that the external flow downstream stagnation point over the upper surface has increased over a longer range. Subsequently, the accelerated flow increased cooling effect and reduced static temperature on upper airfoil surface. Furthermore, the Figure demonstrates that the hot air from piccolo tube holes impinged on LE skin and circulated in the diffuser region before departure lower and upper diffuser spaces created between the internal wall and LE skin. 

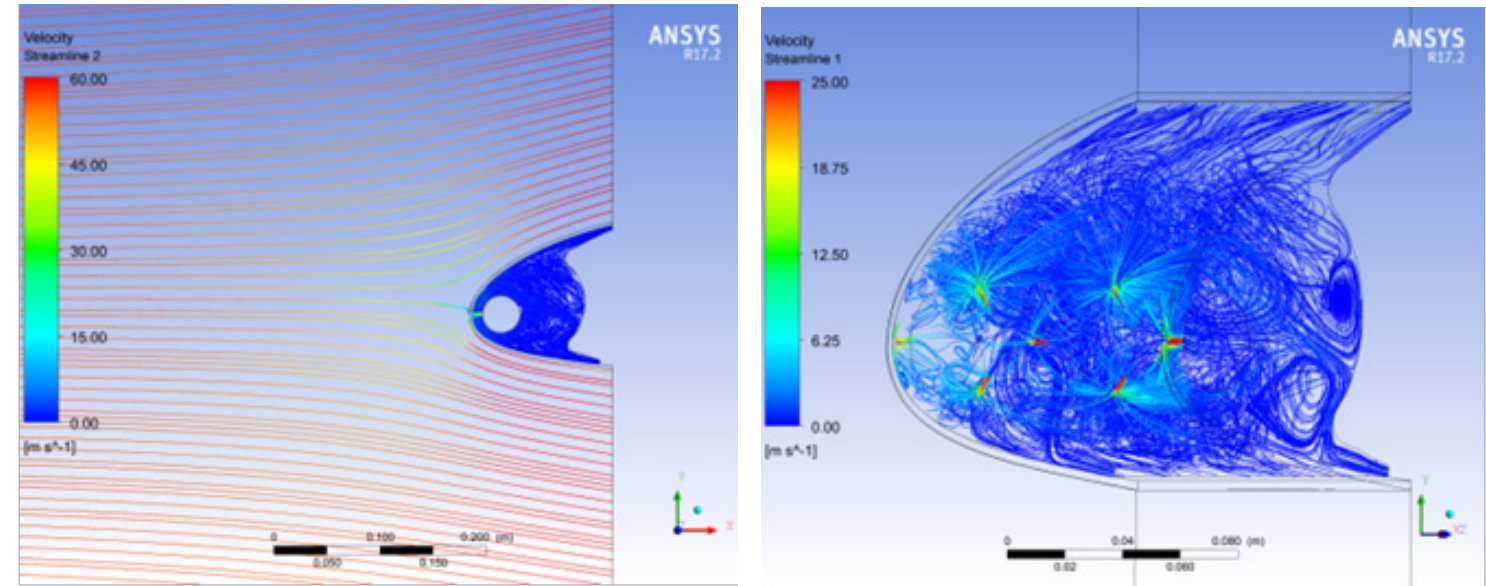

Figure 12 Stream line velocity.

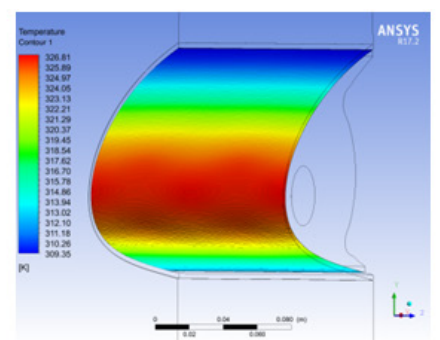

(a)

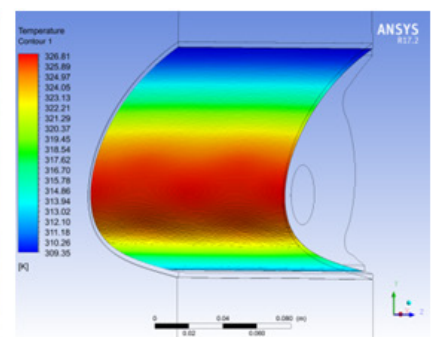

(b)

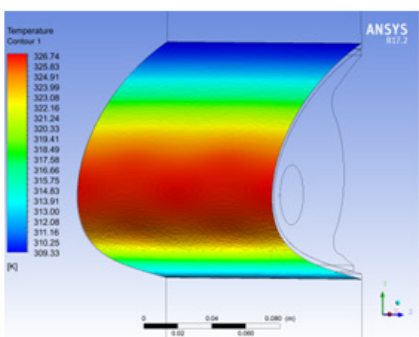

(c)

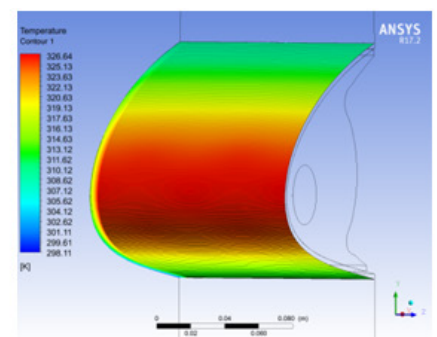

(d)

Figure 13 Pressure gradient contour (a) 2D local values, (b) specific values, (c) 5_spanwise stations and (d) 2D.

The temperature contours shown in Figure 14 correspond to wing's internal and external surfaces corresponds to the LE skin. The contours of the LE skin temperature in Figure 14 Display hot air impingement regions locations.

Figure 15 demonstrates heat flux of the external surface of wing skin given in Figure 15 to be compared with contact cold air layer

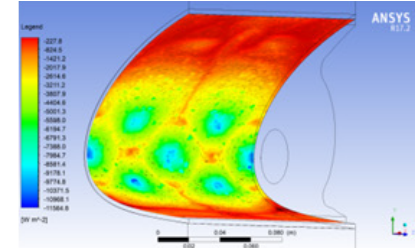

(a)

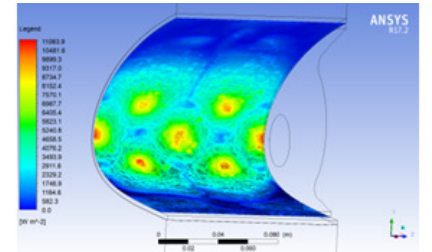

(b) and also the internal surface of the wing and contact hot air layer.The calculated heat flux at location of the jet impingement was highest at each spanwise jet station and decreased quickly away jet station. Note that distribution of heat flux calculated along lower and upper surface at each station of spanwise was not symmetric. As seen in the results at $\mathrm{z}=38.75 \mathrm{~mm}$, the $-45^{\circ}$ jet contributed was high local heat flux compared to the $+45^{\circ}$ jet.

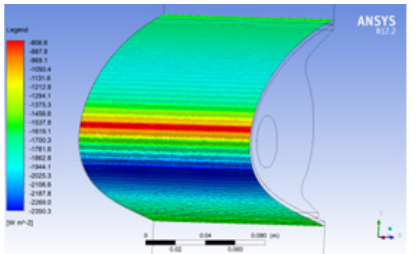

(c)

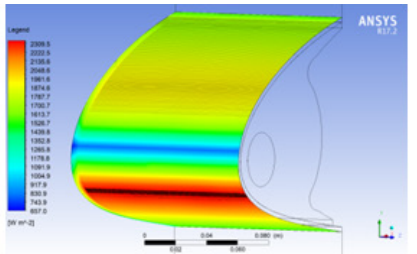

(d)

Figure I4 Temperature contour on wing LE internal (b) and external (c) surfaces and airflow layers contact with LE cold external (a) and hot internal (d).

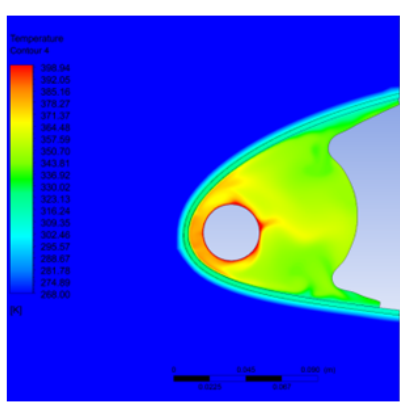

(a)

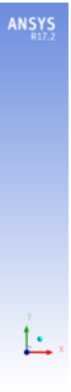

(b)

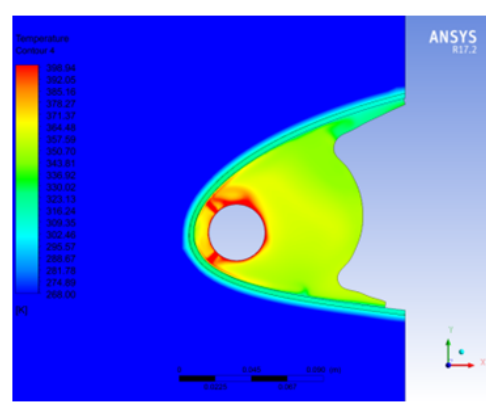

(c)

Figure 15 Heat flux contoure on wing LE internal (b) and external (c) surfaces and airflow layers contact with LE cold external (a) and hot internal (d). 
Figure $16 \& 17$ shows $2 \mathrm{D}$ and sectional contours of temperature and five stations of spanwise containing hot air jets in wing model Figure $16 \& 17$ display sectional contours of temperature and at 2D Figure 16 (a), (b) and (c) and five spanwise stations Figure 17 (a) \& (c) comprising the model hot air jets. Figure 18 show 2D and sectional match number contours of temperature Figure 13 shows that pressure gradient remain high through jet core and above impingement region. Shear of layers jet that bounded the jet core are observable in contour map presented in Figure 13. Figure 18 demonstrates that throughout core of jet and above impingement region pressure gradient stayed high. Also noticeable in the contour maps shown in Figures are the jet shears layer that bordered jet core.

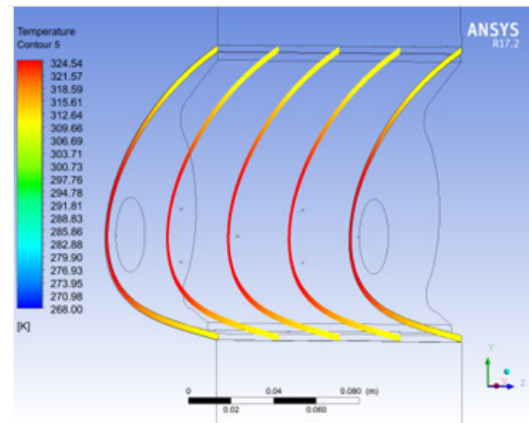

(a)

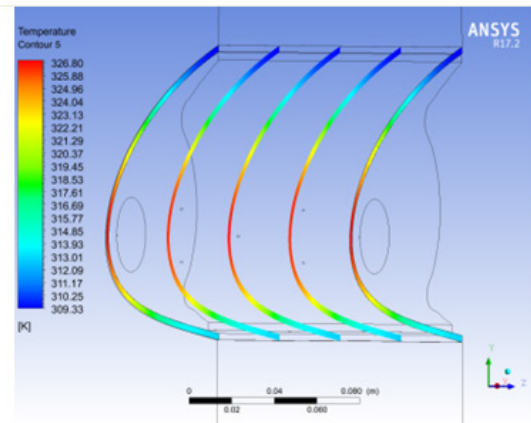

(b)

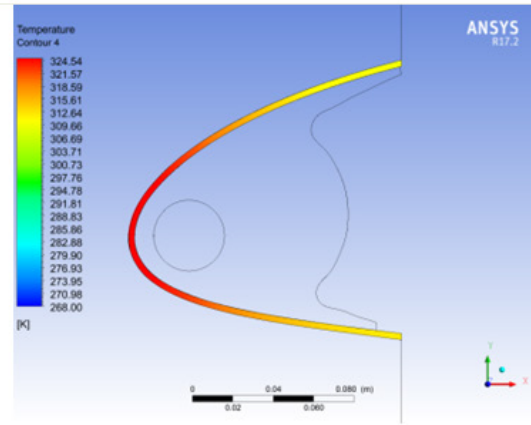

(c)

Figure 16 Temperature contour 2D sections at (a) 0 Jet, (b) I Jet and (c) 2 Jet.

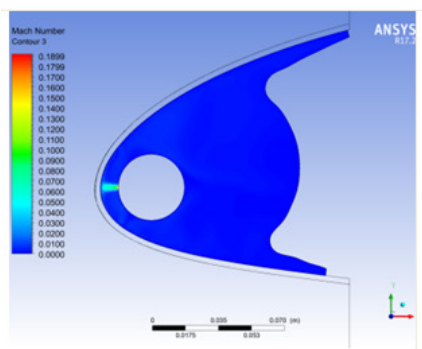

(a)

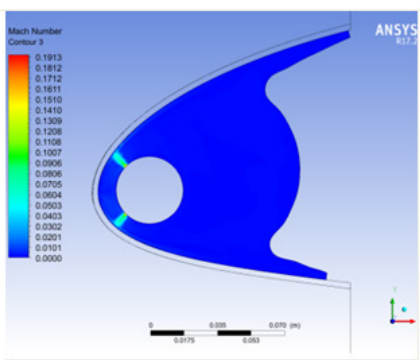

(b)

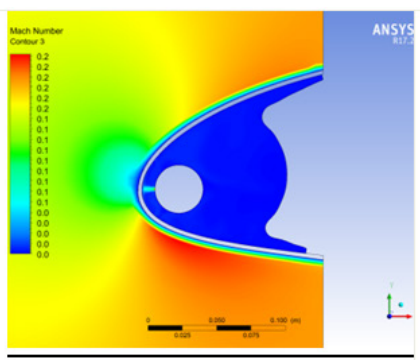

(c)

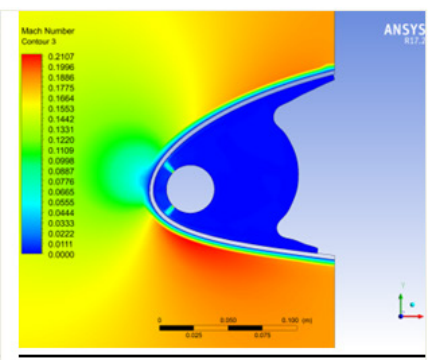

(d)

Figure 17 Temperature contour at five spanwise stations at wing LE (a) Specific temp range , (b) local temp range and (c) 2D.

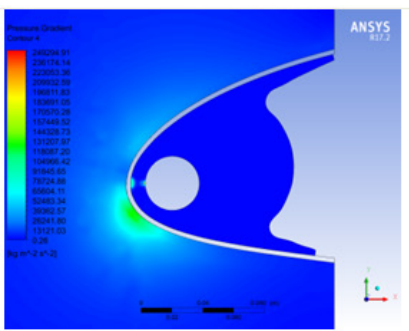

(a)

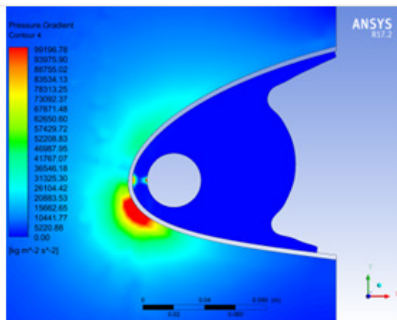

(b)

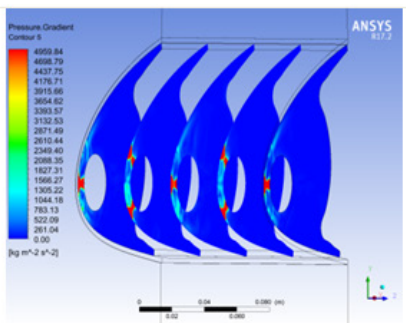

(c)

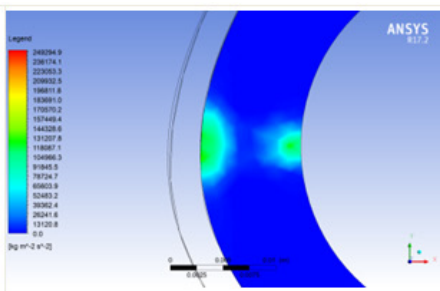

(d)

Figure I 8 Mach contour 2D sections at (a) I Jet, (b) 2 Jet.All domain (c) I Jet, (d) 2 Jet.

\section{Conclusion}

The paper deals with heat transfer between impinging gas jets and solid surfaces through convection. Steady state CFD analysis of the wing's inner and external flow field using ANSYS was performed. By using CFD to predict the performance of the airplane wing Antiice numerical model with NACA 23012 airfoil cross section. On the internal surface of a thickened NACA 23012 airfoil, heating elements are modeled using a K- $\omega$ turbulence model. By study convective, viscous and conductive heat transfer in a dry atmosphere coupling technique was created three domains: external airflow, solid conduction and inner airflow, it is possible to save huge amounts of time and money before testing the wing in the wind tunnel. Calculations indicate that numerically-simulated curve trends are in great consonance with experimentally obtained curve trends. The present paper highlights the continuing advances effects of hot air jets on concave surface as wing LE. In order to keep the outside surface above freezing temperatures, large temperatures are required on the inside surface where the heaters are placed. The study provided shows a powerful opportunity to use computational fluid dynamics in the creation and validation of dynamic wing anti-icing system models.

\section{Funding}

None.

\section{Acknowledgments}

None. 


\section{Conflicts of interest}

The authors declare that there was no conflict of interest.

\section{References}

1. Bernardo B, Alessandra D, Oronzio M, et al. Numerical Investigation on a modified "Piccolo Tube" System In Aircraft Anti-Icing. The American society of Mechanical engineers. 2017:9.

2. Don W, Zhu J, Zheng M, et al. Thermal analysis and testing of nonrotating cone with hot-air anti-icing system. J. Propul. Power. 2015;31(3):1-8.

3. UIUC airfoil coordinates database. 2011.

4. Papadakis M, See-Ho Wong. Parametric Investigation of a Bleed Air Ice Protection System. AIAA. 2006-1013.

5. See Ho Wong, Michael Papadakis, Alonso Zamora. Computational Investigation of a Bleed Air Ice Protection System. AIAA. 2009-3966.
6. Menter FR. Two-equation eddy-viscosity turbulence models for engineering applications. American Institute of Aeronautics and Astronautics Journal. 1994;32(8):1598-1605.

7. Ridha Hannat, François Morency, Louis Decoster. Numerical study of a hot-air-based aircraft wing anti-icing system using the box-behnken doe approach. Transactions of the Canadian Society for Mechanical Engineering. 2013;37(1):111-128.

8. Morency F, Brahimi MT, Tezok F et al. Hot Air Anti-Iicing System Modelization in the Ice Protection Code CANICE. AIAA. 1998.

9. Papadakis M, Wong SH, Yeong HW, et al. Experimental Investigation of a Bleed Air Ice Protection System. SAE International. 2007;116:643-663. 